\title{
A Colorimetric Microplate Assay Method for High Throughput Analysis of Lipase Activity
}

\author{
Suk-Jung Choi*, Jung Min Hwang and Sung Il Kim \\ Department of Chemistry, Kangnung National University, Gangneung 210-702, Korea
}

Received 3 January 2003, Accepted 4 February 2003

\begin{abstract}
The present work describes a colorimetric microplate assay for lipase activity based on the reaction between 5,5'dithiobis(2-nitro benzoic acid) (DTNB) and the hydrolysis product of 2,3-dimercapto-1-propanol tributyrate (DMPTB). Reaction mixtures containing DTNB, DMPTB, and lipase were prepared in microplate wells, and the absorbance at $405 \mathrm{~nm}$ was recorded after incubation at $37^{\circ} \mathrm{C}$ for $30 \mathrm{~min}$. A linear relationship was obtained in the range of 0.1-1 $\mathrm{U}$ of lipase activity by this method. The reaction conditions were also optimized for the range of 0.01-0.1 U or 1-10 U. When assaying crude tissue extracts, the reaction of DTNB with non-specific reducing agents created a major source of error. However, this error was corrected by the use of blank samples that did not contain DMPTB.
\end{abstract}

Keywords: Colorimetric, Lipase assay, Microplate

\section{Introduction}

Lipases (EC 3.1.1.3) catalyze the hydrolysis of triacylglycerols (TAGs), resulting in the release of fatty acids. They are present in many bacteria, fungi, plants, and animals, and have been used in numerous applications in food, cosmetics, detergents, and pharmaceutical industries (Vulfson, 1994). Recently, there have been attempts to use lipase for the deacetylation of cephalosporins (Lee et al., 2001). Lipases have certain roles in human pathogenesis, and their activity modulators have been suggested as potent pharmaceuticals for the treatment of obesity and other diseases (Oglesby and Gorman, 1984; Kubo and Hostetler, 1987; Hadvary et al., 1988; Nonaka et al., 1996; Kawamura et al., 1999; Park, 2001).

*To whom correspondence should be addressed.

Tel: 82-33-640-2306; Fax: 82-33-647-1183

E-mail: sjchoi@kangnung.ac.kr
Many different lipase assays have been developed. Their principles and drawbacks were reviewed by Beisson et al. (2000). Although a microplate-based lipase assay was previously described (Laine et al., 1993), it was reported to be sensitive to artifacts (Beisson et al., 2000). Thus, to our knowledge, there is currently no reliable microplate assay that is suitable for the high throughput analysis of lipase activity. The colorimetric lipase assay, which utilizes 5,5'-dithiobis(2nitro benzoic acid) (DTNB, Ellman's reagent) and 2,3dimercapto-1-propanol tributyrate (DMPTB), was first described by Kurooka et al. (1977). It was later modified for the determination of the positional specificity of non-specific and 1,3-specific lipases (Farias et al., 1997). Free thiol groups that are generated by the lipase hydrolysis of DMPTB reduce DTNB to create a yellow color. Several thioester substrates, other than DMPTB, have also been developed and used for lipase assays (Farooqui et al., 1984; Renard et al., 1987).

The DMPTB-DTNB method has some advantages over other methods. It is simpler and more sensitive when compared to the conventional titrimetric method. In structural similarity, the thioester substrate is closer to TAG than pnitrophenyl esters that are commonly used for colorimetric assays. But, wide application of the method is limited because of the nonspecific reactions of thioester substrates or DTNB. The problem was partly resolved by adding PMSF (phenylmethylsulfonyl fluoride), which could suppress hydrolysis of DMPTB by nonspecific esterases (Kurooka et al., 1977). However, when we applied the method to the assay of squid tissue extracts, significant error was still observed in comparison with the data that were obtained by the titrimetric method.

In the present work, we optimized the DMPTB-DTNB method for the microplate format, and were able to simultaneously determine the lipase activity in many samples over a range of 0.01-10 U. In addition, by using a blank that contained no DMPTB, it was possible to correct for errors that originated from the non-specific DTNB reactions in crude tissue samples. 


\section{Materials and Methods}

Standard assay method A DTNB (Sigma, St. Louis, USA) stock solution $(40 \mathrm{mM})$ was prepared in isobutanol. DMPTB (Aldrich, Milwaukee, USA) $(10 \mathrm{mM})$ was dissolved in $6 \%$ Triton $\mathrm{X}-100,50 \mathrm{mM}$ Tris-Cl, $\mathrm{pH}$ 7.2. The two stock solutions were stored at $-20^{\circ}$ C. Candida rugosa lipase (Sigma L1754, $724 \mathrm{U} / \mathrm{mg}$ of protein, St. Louis, USA) was dissolved in or diluted with buffer L $(10 \mathrm{mM} \mathrm{KCl}, 10 \mathrm{mM}$ Tris-Cl, $\mathrm{pH} 7.5)$. The standard reaction mixture contained $0.2 \mathrm{mM}$ DMPTB, $0.8 \mathrm{mM}$ DTNB, $1 \mathrm{mM}$ EDTA, $0.05 \%$ Triton $\mathrm{X}-100$, and $50 \mathrm{mM}$ Tris-Cl, $\mathrm{pH}$ 7.5. For the preparation of the standard reaction mixture, $20 \mu \mathrm{l}$ of $10 \mathrm{mM}$ DMPTB, $20 \mu \mathrm{l}$ of $40 \mathrm{mM}$ DTNB, $2 \mu \mathrm{l}$ of $0.5 \mathrm{M}$ EDTA, $5 \mu \mathrm{l}$ of $10 \%$ Triton $\mathrm{X}-100$, and $50 \mu \mathrm{l}$ of $1 \mathrm{M}$ Tris-Cl, $\mathrm{pH} 7.5$ were mixed in a microcentrifuge tube and $803 \mu \mathrm{l}$ of deionized water was added to make a final volume of $900 \mu \mathrm{l}$. Microplate wells were filled with $180 \mu \mathrm{l}$ of this mixture and $20 \mu \mathrm{l}$ of the enzyme sample was added to each well. For the specific detection of lipase activity in tissue crude extracts, we used a blank that contained no DMPTB. The microplate was immediately transferred to a $37^{\circ} \mathrm{C}$ incubator to start the reaction. After the indicated period of incubation, the absorbance of each well at $405 \mathrm{~nm}$ was measured using a SpectraCount microplate reader (Packard Instrument Company, Meriden, USA).

Time and dose dependence The time-dependent absorbance change was monitored for the optimizing-assay conditions. Each reaction mixture was prepared according to the standard assay method. The microplate was incubated at $37^{\circ} \mathrm{C}$, and the absorbance was recorded at different time points. For the evaluation of the linearity of the method, the reaction mixtures were prepared with different amounts of lipase that ranged from 0.1 to $0.8 \mathrm{U}$, incubated at $37^{\circ} \mathrm{C}$ for $30 \mathrm{~min}$, and processed by the standard assay method. The incubation time was adjusted to $10 \mathrm{~min}$ for $1-10 \mathrm{U}$ and $3.5 \mathrm{~h}$ for 0.01-0.1 $\mathrm{U}$ of lipase. For detection of the lipase that are less than $0.1 \mathrm{U}$, the concentrations of DMPTB and DTNB were lowered to $0.05 \mathrm{mM}$ and $0.2 \mathrm{mM}$, respectively, and bovine serum albumin (BSA) (Sigma, St. Louis, USA) was added at a concentration of $0.01 \mathrm{mg} / \mathrm{ml}$.

Titrimetric assay For the titrimetric lipase assay, a substrate solution was prepared with $2 \%$ olive oil, $8 \mathrm{mg} / \mathrm{ml}$ gum Arabic, and $26.7 \mathrm{mM}$ Tris- $\mathrm{Cl}, \mathrm{pH}$ 8.0. The solution was emulsified by sonication. Each reaction mixture contained a $6.5 \mathrm{ml}$ substrate solution and $1 \mathrm{ml}$ enzyme. After incubation at $37^{\circ} \mathrm{C}$ for $30 \mathrm{~min}$, several drops of the thymolphthalein indicator solution were added and the mixture was titrated to a light blue color with a $5 \mathrm{mM}$ $\mathrm{NaOH}$ solution.

\section{Results and Discussion}

Time and dose dependence As shown in Fig. 1, the initial reaction rate increased with the increasing amount of lipase. The reaction mixture that contained $10 \mathrm{U}$ lipase showed a linear absorbance change up to $10 \mathrm{~min}$, with absorbance reaching a plateau above 1.88 absorbance unit after further

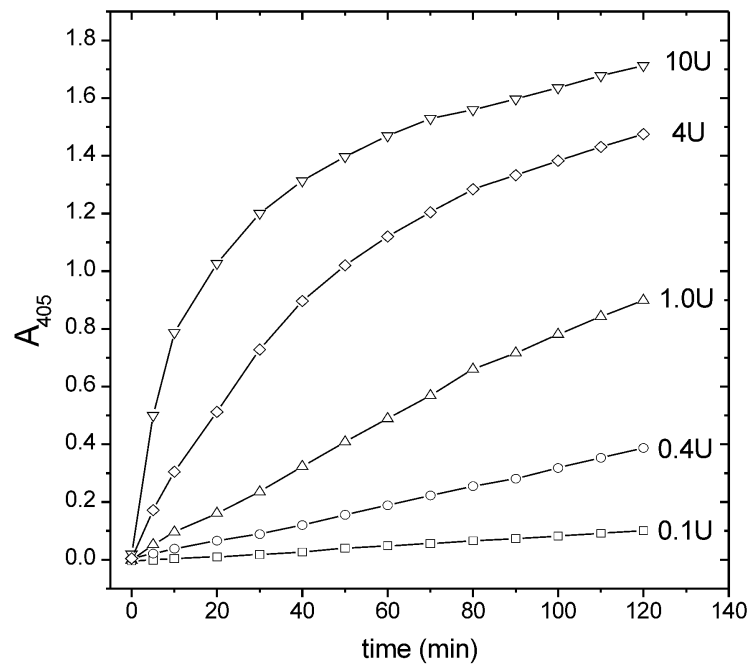

Fig. 1. Time-dependent absorbance changes using different amounts of lipase. Standard reaction mixtures were prepared with $0.1,0.4,1.0,4.0$, and $10 \mathrm{U}$ lipase, and incubated at $37^{\circ} \mathrm{C}$. The absorbance was recorded at different time points.

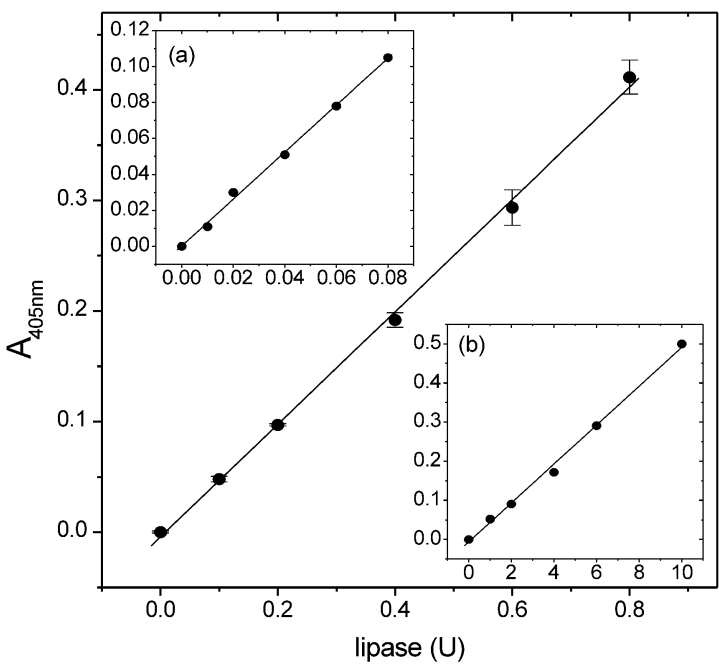

Fig. 2. Linearity evaluation. Reaction mixtures were prepared with different amounts of lipase that ranged from 0.1 to $0.8 \mathrm{U}$, incubated at $37^{\circ} \mathrm{C}$ for $30 \mathrm{~min}$, and processed by the standard assay method. Each data point represents the mean from triplicate determinations, and the error bar represents the standard deviation. For more sensitive detection of lipase activity, concentrations of DMPTB and DTNB were lowered to $0.05 \mathrm{mM}$ and $0.2 \mathrm{mM}$ respectively, and $0.01 \mathrm{mg} / \mathrm{ml} \mathrm{BSA}$ was added. The reaction mixtures were incubated at $37^{\circ} \mathrm{C}$ for $3.5 \mathrm{~h}$ (inset a). For the detection of larger amounts of lipase, standard reaction mixtures were prepared with different amounts of lipase that ranged from 1 to $10 \mathrm{U}$ and incubated at $37^{\circ} \mathrm{C}$ for $10 \mathrm{~min}$ (inset b).

incubation. With these results, the incubation time was optimized for different ranges of lipase activity. In the case of the Candida rugosa lipase that was used in this experiment, linearity was obtained in the range of $0.1-1 \mathrm{U}$ by a $30 \mathrm{~min}$ 


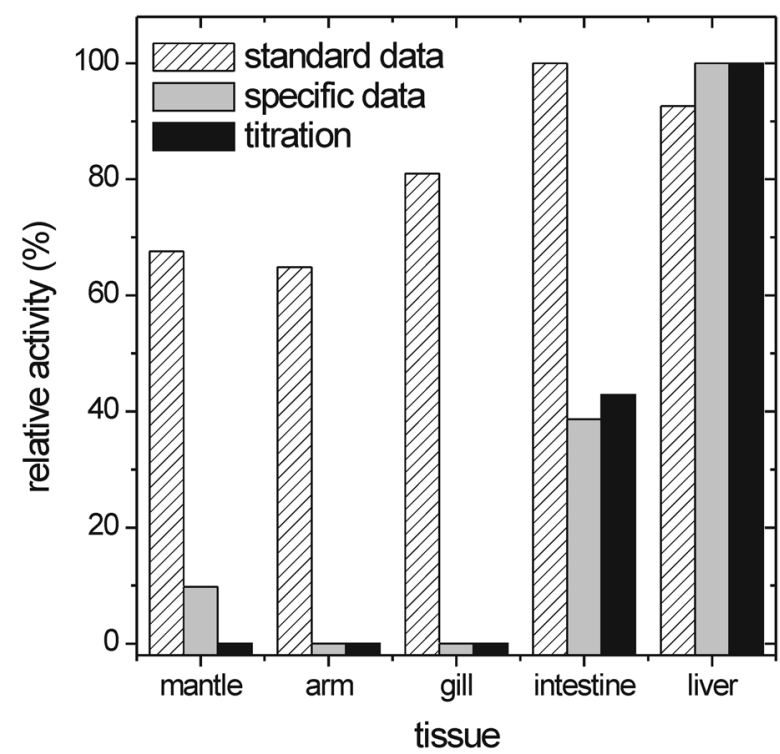

Fig. 3. Specific detection of lipase activity in crude tissue extracts. A blank reaction mixture without DMPTB was made for each standard reaction mixture. Specific data were calculated by subtracting the blank value from the standard assay data. The relative activity was calculated as a percent of the highest activity.

incubation (Fig. 2), whereas 10 min was suitable for the 1-10 $\mathrm{U}$ range (inset b of Fig. 2). A longer incubation was also tried for the detection of $0.01-0.1 \mathrm{U}$ of lipase. However, the activity was always underestimated, due to the inactivation of lipase during the incubation period. Therefore, BSA was added at a concentration of $0.01 \mathrm{mg} / \mathrm{ml}$ as a protein stabilizer. In addition, the concentrations of DMPTB and DTNB were lowered to $0.05 \mathrm{mM}$ and $0.2 \mathrm{mM}$, respectively, since only a minute fraction of the substrates was consumed. With these modifications, $0.01 \mathrm{U}(13.8 \mu \mathrm{g})$ lipase activity was accurately estimated after $3.5 \mathrm{~h}$ incubation at $37^{\circ} \mathrm{C}$ (inset a of Fig. 2). The absorbance change was linear during the incubation period, and the reaction rate also correlated well with the amount enzyme (data not shown).

Specific detection of lipase in crude samples When we estimated the lipase activity in the extracts of different tissues from squid, there was a large discrepancy between the data that were obtained by the standard DMPTB-DTNB method and the data that were obtained using the conventional titrimetric assay method (Fig. 3). There are two reasons for this discrepancy; DTNB reacting with non-specific reducing agents, and DMPTB hydrolysis by non-specific tissue esterases (Kurooka et al., 1977). The contribution of esterases was considered negligible since PMSF was added during the preparation of the tissue extracts, and the majority of the esterase activity was irreversibly inhibited by PMSF (Kurooka et al., 1977). Moreover, in the cases where the samples showed a discrepancy, the yellow color developed immediately after the reaction mixtures were prepared and the intensity remained almost constant during the incubation period. In contrast, the liver sample (which showed no discrepancy between the assays) showed a gradual increase in color intensity. We concluded, therefore, that the majority of the non-specific color originated from the reaction between DTNB and the non-specific reducing agents. In order to correct the effect of the non-specific reducing agents, a blank reaction mixture without DMPTB was then made for each standard reaction mixture. The blank should represent the reaction of DTNB with the non-specific reducing agents. By subtracting the blank value from the standard assay data, specific data (i.e. absorbance change contributed only by lipase) were calculated. The data presented in Fig. 3 show that this specific data correlated well with the titrimetric assay which had previously been considered as the most reliable method.

In conclusion, the DMPTB-DTNB reaction system was successfully applied to the microplate format. By varying the reaction conditions, it was possible to precisely measure the lipase activity from 0.01 to $10 \mathrm{U}$. In addition, the problem of non-specific reactions was resolved by the use of a blank.

Acknowledgments This work was supported by the Korea Science and Engineering Foundation (KOSEF) through the East Coastal Marine Bioresources Research Center at the Kangnung National University, Gangneung, Korea.

\section{References}

Beisson, F., Tiss, A., Rivière, C. and Verger, R. (2000) Methods for lipase detection and assay: a critical review. Eur. J. Lipid Sci. Technol. 2, 133-153.

Farias, R. N., Torres, M. and Canela, R. (1997) Spectrophotometric determination of the positional specificity of nonspecific and 1,3-specific lipases. Anal. Biochem. 252, 186-189.

Farooqui, A. A., Taylor, W. A., Pendley, C. E. II, Cox, J. W. and Horrocks, L. A. (1984) Spectrophotometric determination of lipases, lysophospholipases, and phospholipases. J. Lipid Res. 25, 1555-1562.

Hadvary, P., Lengsfeld, H. and Wolfer, H. (1988) Inhibition of pancreatic lipase in vitro by the covalent inhibitor tetrahydrolipstatin. Biochem. J. 256, 357-361.

Kawamura, I., Yamamoto, N., Sakai, F., Yamazaki, H., Naoe, Y., Inami, M., Manda, T. and Shimomura, K. (1999) Activation of lipoprotein lipase and inhibition of B16 melanoma-induced cachexia in mice by ponalrestat, an aldose reductase inhibitor. Anticancer Res. 19, 341-348.

Kubo, M. and Hostetler, K. Y. (1987) Inhibition of purified bovine milk lipoprotein lipase by propranolol and other beta-adrenergic blockers in vitro. Biochim. Biophys. Acta 918, 168-174

Kurooka, S. Okamoto, S., and Hashimoto, M. (1977) A novel and simple colorimetric assay for human serum lipase. J. Biochem. 81, 361-369.

Laine, J., Beattie, M. and LeBel, D. (1993) Simultaneous kinetic 
determinations of lipase, chymotrypsin, trypsin, elastase, and amylase on the same microtiter plate. Pancreas 8, 383-386.

Lee, H.-W., Ko, J.-Y., Kim, W. J., and Byun, S. M. (2001) Isolation, analysis, and expression of lipase with cephalosporinC deacetylation activity from Staphylococcus sp. J. Biochem. Mol. Biol. 34, 274-277.

Nonaka, Y., Ohtaki, H., Ohtsuka, E., Kocha, T., Fukuda, T., Takeuchi, T. and Aoyagi, T. (1996) Effects of ebelactone B, a lipase inhibitor, on intestinal fat absorption in the rat. $J$. Enzyme Inhib. 10, 57-63.

Oglesby, T. D. and Gorman, R. R. (1984) The inhibition of arachidonic acid metabolism in human platelets by RHC
80267, a diacylglycerol lipase inhibitor. Biochim. Biophys. Acta 793, 269-277.

Park, B. -H. (2001) Inactive but dimeric form of lipoprotein lipase in human plasma. J. Biochem. Mol. Biol. 34, 329-333.

Renard. G., Grimaud. J., El Zant, A., Pina, M. and Graille, J. (1987) An improved method for the colorimetric assay of lipase activity using an optically clear medium. Lipids 22, 539541.

Vulfson, E. N. (1994) Industrial applications of lipases; in Lipases; Their Structure, Biochemistry, and Application Woolley, P. and Petersen, S. B. (eds.), pp. 271-288, Cambridge University Press, New York, USA. 